\title{
LITIGIOSIDADE REPETITIVA E PADRONIZAÇÃO DECISÓRIA: o incidente de resolução de demandas repetitivas e sua consolidação perante o Superior Tribunal de Justiça
}

\author{
REPEAT LITIGIOSITY AND DECISION STANDARDIZATION: the repetitive demands \\ incident resolution and its consolidation towards the Superior Court of Justice
}

Recebimento em 22/02/2021

Patrícia Almeida Campos Borges ${ }^{1}$

Aceito em 22/05/2021

\section{RESUMO}

Este artigo tem por escopo o estudo sobre o incidente de resolução de demand as repetitivas, novo mecanismo processual inaugurado com o Código de Processo Civil de 2015. Deste modo, este paper fora desenvolvido em três partes, sendo que a primeira discorre sobre os primeiros passos do IRDR no contexto do ordenamento jurídico processual, arguindo sobre a litigiosidade de massa e a necessidade de padronização decisória. Já na segunda parte, são abordadas as principais nuances dos requisitos legais exigidos para a instauração do incidente, que são a efetiva repetição de processos e o risco à isonomia e segurança jurídica. Na terceira e última parte do artigo, discorre-se sobre as principais decisões do Superior Tribunal de Justiça no que tange as controvérsias que permeiam o IRDR, e como esse cenário tem contribuído para a consolidação do incidente em testilha. Desta forma, a pesquisa foi precipuamente bibliográfica, utilizando-se os métodos qualitativo e dedutivo de análise de dados.

Palavras-chave: Litigiosid ade. Padronização. Precedentes. Isonomia. Segurança Jurídica.

\section{ABSTRACT}

The purpose of this article is the study on the repetitive demands incident resolution, a new procedural mechanism opened with the Civil Procedure Code of 2015. Thus, this paper was developed in three parts, the first of which discusses the first steps of the IRDR in the context of the procedural legal system, arguing about mass litigation and the need for standardized decisionmaking. In the second part, the main nuances of the legal requirements required for the establishment of the incident are addressed, which are the effective repetition of processes and the risk to isonomy and legal security. In the third and last part of the article, we discuss the main decisions of the Superior Court of Justice regarding the controversies that permeate the IRDR, and how this scenario has contributed to the consolidation of the incident on screen. So, the research was primarily bibliographic, using qualitative and deductive data analysis methods.

Keywords: Litigation. Standardization. Precedents. Isonomy. Legal Security.

\section{INTRODUÇÃ̃O}

\footnotetext{
${ }^{1}$ Mestranda do Programa de Pós-graduação Stricto Sensu em Direito pela Universidade Federal de Mato Grosso (UFMT). Especialista em Direito Processual pela Pontifícia Universidade Católica de Minas Gerais (PUC Minas). Especialista em Direito do Trabalho e Processual do Trabalho, pela Universidade Cândido Mendes (UCAM) e pelo Centro Universitário Várzea Grande (UNIVAG). Graduada em Direito pela Universidade de Cuiabá (UNIC). Advogada Licenciada. Assessora Jurídica no Tribunal de Justiça de Mato Grosso (TJMT).
} 


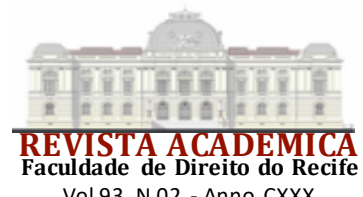

Vol.93 N.02 - Anno CXXX

Definitivamente o Incidente de Resolução de Demandas Repetitivas é uma das mais profundas e importantes modificações inauguradas pelo Código de Processo Civil de 2015, afinal, diante do cenário jurídico brasileiro de litígios envolvendo questões repetitivas, os chamados processos de massa, a criação de um instituto que visa a dar celeridade e segurança jurídica na resolução dessas questões, com a padronização decisória veio a calhar.

O modelo constitucional do processo civil contemporâneo impulsiona os institutos processuais ao alcance de um processo mais efetivo e célere. E neste cenário, o IRDR tem um importante papel, na medida em que se reveste de mecanismo ideal no trato da litigiosidade de massa, fixando tese jurídica a ser aplicada nos casos presente e futuros, cuja questão de direito seja afeta a questão decidid a no incidente, concretizand o a necessidade de padronização decisória.

Entender os requisitos de cabimento do incidente é de suma importância, pois aqueles refletem a própria razão de ser o IRDR, que é justamente alcançar um grupo de demandas que se repetem e cujas questões de direito comuns precisam ser decididas de forma igualitária, equânime, sob pena de se violar a isonomia e a segurança jurídica, princípios insertos na Constituição Federal.

Por se tratar de um procedimento novo, sem precedentes no código anterior, é natural que surjam controvérsias e debates em torno do incidente de resolução de demanda repetitivas, e nesse pouco tempo de vigência do novo CPC já é possível perceber que algumas dessas questões já foram examinadas pelo Superior Tribunal de Justiça, decisões que impactam sobremaneira o curso dos processos em nosso país, contribuindo para a consolidação do IRDR.

\section{LITIGIOSIDADE REPETITIVA E NECESSIDADE DE PADRONIZAÇÃO DECISÓRIA: OS PRIMEIROS PASSOS DO IRDR NO BRASIL}

Não há que se olvidar que a ratio do novo Código de Processo Civil está voltada à constitucionalização do processo, ou seja, sua coligação harmônica com os preceitos constitucionais, no intuito de democratizá-lo e chamando todos os sujeitos processuais a uma atuação mais efetiva no contexto do processo democrático, cada qual cumprindo suas devidas funções, em prol de um processo mais simples, justo, célere e equânime ${ }^{2}$.

Neste cenário, quando do anteprojeto do novo Estatuto Processual Civil, a comissão de juristas formada estava imbuída do desejo de fortalecer os precedentes judiciais, ante a crescente aproximação das tradições jurídicas do civil law e common law, e a crise na prestação jurisdicional, que se tornou cada vez mais morosa e, diga-se, menos efetiva. E assim surgiu, primeiramente, em documento subscrito ${ }^{3}$ por Luiz Fux, Presidente da Comissão de Juristas, a "proposta de instituição de um incidente de coletivização dos denominados litígios de massa, a qual evitará a multiplicação das demandas".

É cediço que o Judiciário de nosso país tem servido de porta de acesso à justiça a todos os cidadãos, independente de raça, cor, cred o ou capacidade financeira. As relações interpessoais têm se intensificado, a comunicação se tornou mais instantânea graças aos avanços tecnológicos, a sociedade do hiperconsumo já é uma realidade há muito tempo, e com isso as inúmeras controvérsias surgidas têm resultado em lides judiciais, numa constante crescente, e todo esse

2 "Se, de um lado, os juristas veem a litigiosidade aumentar, veem também, de outro, um ingrediente "novo" com o qual lidar, para resolvê-la: a norma constitucional. Evidentemente, a existência de uma norma constitucional, em si, não é um dado novo. O que de novo surgiu, no final do século XX e começo do século XXI, foi um novo sentimento constitucional: à Constituição passa-se a reconhecer efetiva força normativa. Reconhece-se, então, a supremacia da Constituição.”. (MEDINA, José Miguel Garcia. Curso de direito processual civil moderno. 3. ed. rev. atual. e ampl. São Paulo: Editora Revista dos Tribunais, 2017, p. 15)

${ }^{3}$ Este documento pode ser encontrado em

https://www.migalhas.com.br/quentes/101614/ministro-luiz-fux-comenta-a-reformulacao-do-cpc.

Acesso em: 10 mar. 2020. 


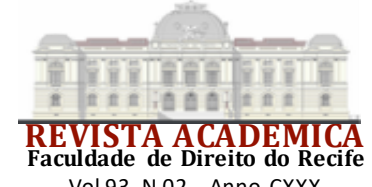

Vol.93 N.02 - Anno CXXX

\begin{abstract}
pretensão processual relativa à relação jurídica substancial posta à apreciação do Poder Judiciário. Ocorre que "questões", correspondem às diversas providências em que deve enfrentar o Poder Judiciário para pôr fim ao processo e, por conseguinte, numa única "demanda" pode haver diversas "questões" de fato ou de direito controvertidas de que depende o pronunciamento judicial, constituindo elemento objetivo da "demanda". Dessa forma, é cabível a instauração do incidente quando houver simultaneamente: risco de ofensa à isonomia e à segurança jurídica e efetiva repetição de processos que contenham a mesma controvérsia sobre "questão" unicamente de direito (art. 976, I e II, CPC/2015). Isso tem grande importância, já que as demandas repetitivas, embora dependam de julgamento de mesma "questão", certamente podem exigir a consideração de outras circunstâncias, que variarão conforme cada uma das ações individuais.
\end{abstract}

Não se analisam questões de fato e questões de direito heterogêneas, o que impede que se possa falar em julgamento da demanda, que depende necessariamente da análise da causa de pedir e do pedido, ao contrário do que ocorre no regime alemão (Musterverfahren).

Portanto, não há que se confundir questão com demanda, pois o IRDR é um incidente processual que tem por finalidade "auxiliar no dimensionamento da litigiosidade repetitiva mediante uma cisão da cognição através do procedimento-modelo" (NUNES, 2015), abrangendo somente questões comuns a todos os casos similares (MARINONI, 2016, p. 58-59), que serão afetados com a decisão de admissibilidade do incidente, e a decisão de cada caso concreto continuará sob a condução do juiz do processo originário, que aplicará a decisão padrão - tese jurídica fixada no IRDR - considerando as peculiaridades fático-probatórias de cada caso.

Importante pontuar acerca da separação entre questões de fato e questões de direito (pilares da jurisd ição), mais acentuada com o NCPC e o sistema de demandas repetitivas e vinculação de precedentes. Neste sentido, ressalta que a distinção entre questão de direito e questão de fato revela-se tarefa impossível, "já que o fenômeno direito ocorre, efetivamente, no momento de incidência da norma, no mundo real, no universo empírico. Assim, na verdade o direito acontece quando se encontram o mundo dos fatos com o mundo das normas" (WAMBIER, 1998, p. 52-70).

De igual forma, para Didier Jr e Cunha, essa tarefa de distinguir fato e direito não é simples, tendo aduzido o autor que a eficácia jurídica surge após a incidência da hipótese normativa no suporte fático concreto, assim "na tarefa de aplicação do direito, o julgador haverá de examinar, inexoravelmente, questões de fato (quaestiones facti) e questões de direito (quaestiones iuris)" (DIDIER JR.; CUNHA, 2016, p. 438).

No tocante ao incidente de resolução, especificamente, a jurista Sofia Temer enfatiza que "se o aspecto problemático for predominantemente jurídico, por não compreender a aferição, em concreto, dos fatos alegados, estar-se-á diante de uma questão de direito" (TEMES, 2017, p. 72), e na mesma linha de raciocínio, Marinoni (2016, p. 54) adverte que

(...) o incidente supõe a individualização ou o isolamento de uma questão de direito, que embora possa estar claramente apoiada em fatos, não pode exigir investigação probatória. (...) Portanto, há 'questão unicamente de direito', para ef eito de incidente de resolução, quando a questão reclama mera interpretação de norma ou solução jurídica com base em substrato fático incontroverso.

\title{
Mendes (2017, p. 111-113) esclarece que
}

As questões de fato, que poderão ou não guardar também identidade, embora possam ser admitidas como passíveis de apreciação concentrada em outros ordenamentos, como no Musterverfahren alemão, não foram concebidas dentro do objeto de apreciação do Incidente de Resolução de Demandas Repetitivas, segundo a previsão expressa do Código de Processo Civil. Isso não significa, contudo, que para a resolução dos casos concretos, não haja a necessidade de 


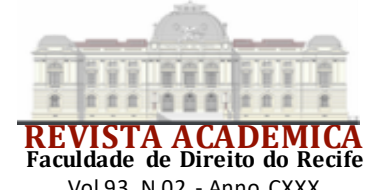

Vol.93 N.02 - Anno CXXX

aferição, e eventual produção de prova, em relação às questões fáticas. Mas, esta análise, segundo o sistema brasileiro concebido, deverá ser feita em momento posterior e de modo individualizado em cada processo.

Desta feita, no incidente de resolução de demanda repetitivas não são apurados se e como ocorreram determinados fatos específicos, mas o tribunal apenas se ocupará de definir a compreensão dos textos normativos, considerando, para tanto, uma categoria fática pressuposta.

Outro requisito obrigatório para a instauração do incidente de resolução é o risco de ofensa à isonomia e à segurança jurídica. Segundo Silva (2006, p. 133), a segurança jurídica consiste no "conjunto de condições que tornam possível às pessoas o conhecimento antecipado e reflexivo das consequências diretas de seus atos e de seus fatos à luz da liberdade reconhecida". Por sua vez, o princípio da isonomia vem insculpido no caput do artigo $5^{\circ}$ da Constituição Federal de 1988, pelo qual é assegurada a iguald ade a todos os cidadãos, sem qualquer distinção.

Mendes e Temer (2015, p. 283-331) ensinam que:

O incidente de resolução de demandas repetitivas, técnica processual destinada a contingenciar litígios seriados, assenta-se em três pilares principais, quais sejam: o princípio constitucional da isonomia, que exige o tratamento uniforme dos litígios isomórficos, a segurança jurídica, estampada na previsibilidade e uniformidade das decisões judiciais e, por fim, a prestação jurisdicional em tempo razoável. Tais princípios, além de nortearem todo o ordenamento jurídico processual (como se infere, dentre outros, dos arts. $1^{\circ}$ a 12 do CPC/2015), são a base constitucional do incidente ora analisado.

É preciso lembrar que no Anteprojeto do Código Processo Civil, aprovado no Senado, continha a previsão de que o IRDR pudesse ser instaurado de modo preventivo, ou seja, nas situações em que houvesse controvérsia com potencialidade de gerar multiplicação de processos. Todavia, alguns juristas se posicionaram contra esse entendimento, pois padrões decisórios não podem "empobrecer o discurso jurídico" bem como porque a decisão do IRDR deve "implementar uma interpretação idônea e panorâmica da temática ali discutida, afinal "seu papel deve ser o de uniformizar e não o de prevenir um debate" (NUNES, 2012).

Já no texto aprovado, o Código de Processo Civil de 2015 abandonou a decisão padrão preventiva no IRDR, passando a exigir a efetiva repetição de processos, com a necessidade de "identificação da divergência demonstrada a partir de julgamentos ocorridos em causas envolvendo pretensões isomórficas" (THEODORO JR. et al, 2016, p. 451), o que contribui sobremaneira para a garantia da isonomia e segurança jurídica.

Acerca de repetição de processo, sabe-se que o CPC não estabelece o requisito quantitativo específico, todavia, a fim de sanar essa lacuna, a repetição de demandas deve ser analisada sob o prisma da ofensa ou não à segurança jurídica. Quer dizer, o risco à isonomia e à segurança jurídica estará presente na medida em que houver ações repetitivas, em número suficiente a se perceber a existência de inúmeras decisões conflitantes sobre a mesma questão de direito.

Mendes adverte que a "simples existência de vários processos em tramitação perante órgãos judiciais já potencializaria um risco eventual de fossem decididos de modo diverso", mas há a necessidade também de que a controvérsia "esteja efetivamente ensejando divergência no seio do Poder Judiciário, capaz de comprometer, de fato, o princípio da isonomia e da segurança jurídica" (MENDES, 2017, p. 113). ${ }^{8}$

${ }^{8}$ Digna de registro a ementa da decisão do Tribunal de Justiça de Mato Grosso, nos autos do processo $\mathrm{n}^{\circ}$ 1007117-52.2017.8.11.0000, que inadmitiu IRDR por reconhecer sua inocuidade para fins de afastar o risco à isonomia e segurança jurídica: "AGRAVO INTERNO — INCIDENTE DE RESOLUÇÃO DE DEMANDAS REPETITIVAS - INCLUSÃO DAS TARIFAS DE USO DO SISTEMA DE DISTRIBUIÇÃO (TUSD) E USO DO SISTEMA DE TRANSMISSÃO (TUST) NA BASE DE 
Segundo Marinoni (2016, p. 63-64),

o legislador misturou requisitos para a instauração do incidente com os seus objetivos ou com os fundamentos teóricos que o legitimam. O risco de ofensa à isonomia e à segurança jurídica não pode ser visto como requisito para a instauração do incidente, uma vez que é inevitável decorrência da repetição de processos em que se controverte uma mesma questão de direito. A isonomia e a segurança jurídica são justificativas teóricas de um sistema de precedentes. É preciso que o "sentido" do direito delineado pela Corte Suprema por intermédio do precedente paute a solução dos casos iguais ou similares, vinculando os juízes e tribunais. A igualdade perante as decisões judiciais é fruto do dever de o Estado dar a todos que estão em uma mesma situação jurídica a solução que a Corte Suprema racionalmente delineou, oferecendo as melhores razões possíveis.

O autor ensina ainda que é preciso diferenciar o objeto do sistema de precedentes e aquele do IRDR. No primeiro "há definição do sentido de direito que deve orientar a vida em sociedade e regular os casos futuros". Já no IRDR, a questão deve ser idêntica entre os casos afetados, bem como há de se resguardar a representatividade adequada durante o processamento do incidente, garantindo-se o contraditório, embora haja disposição legal expressa de observância obrigatórias das decisões proferidas nos autos do incidente de resolução.

Elucida Nunes (2012) que é "necessária a demonstração do efetivo dissenso interpretativo e não um dissenso potencial, sob pena de se instaurar a possibilidade da vedada padronização preventiva", enfrentando-se todos os fundamentos suscitados concernentes à tese jurídica discutida, nos termos do art. $981, \S 2^{\circ}$ do CPC. Enfim, o risco à isonomia e à segurança jurídica deve ser comprovado para a instauração do IRDR, cuja concretude será avaliada pelo órgão colegiado do tribunal, quando do juízo de admissibilidade do incidente, em razão da efetiva repetição de processos contendo a mesma controvérsia unicamente de direito.

\section{O SUPERIOR TRIBUNAL DE JUSTIÇA E A CONSOLIDAÇÃO DO INCIDENTE DE RESOLUÇÃ O DE DEMANDA REPETITIVAS}

Como dito, o incidente de resolução de demandas repetitivas, novidade do novo Código de Processo Civil, tem causado impacto na comunidade jurídica, porém muitas dúvidas e controvérsias ainda pairam sobre os estudiosos do assunto. Certo é que esse debate em torno do incidente chegou aos auspícios do Superior Tribunal de Justiça, que vem proferindo decisões de amplo espectro, e que têm auxiliado na consolidação do mecanismo processual em espeque.

CÁLCULO DO ICMS INCIDENTE SOBRE A ENERGIA ELÉTRICA - UNIDADE DE ENTENDIMENTO DAS CÂMARAS DE DIREITO PÚBLICO E COLETIVO DO TRIBUNAL DIVERGÊNCIA SOBRE A MATÉRIA NO ÂMBITO DO SUPERIOR TRIBUNAL DE JUSTIÇA INOCUIDADE DA INSTAURAÇÃO DO INCIDENTE. Constatada a unicidade de entendimento das Câmaras de Direito Público e Coletivo do Tribunal sobre a não inclusão das Tarifas de Uso do Sistema de Distribuição (TUSD) e de Uso do Sistema de Transmissão (TUST) na base de cálculo do ICMS incidente sobre a energia elétrica, bem como que a divergência de entendimento reside no Superior Tribunal de Justiça, não se mostra juridicamente admissível a instauração do Incidente de Resolução de Demandas Repetitivas, visto que se prestaria, ao fim e ao cabo, tão somente para a suspensão dos processos pendentes, individuais ou coletivos, que tramitam no Estado de Mato Grosso, em prejuízo unicamente dos contribuintes, obrigados a recolher tributo acima do valor que o Tribunal entende devido. De fato, presente a divergência sobre a questão entre a Primeira e a Segunda Turmas do Superior Tribunal de Justiça, a instauração do Incidente de Resolução de Demandas Repetitivas pelo Tribunal, não afastaria o risco de ofensa à isonomia e à segurança jurídica, a revelar a sua inocuidade para esta finalidade. Recurso não provido." 


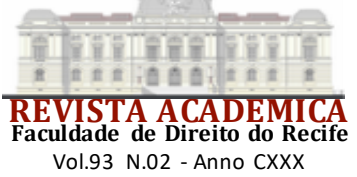

De início, é de bom alvitre ressaltar a recente decisão do Superior Tribunal de Justiça, ao julgar o Recurso Especial $n^{\circ}$ 1.846.109/SP, que consolidou o entendimento de que há um "microssistema de julgamento de questões repetitivas", consignando que o procedimento para distinção dos casos suspensos em razão de afetação de matéria pelo rito dos Recursos Repetitivos (art. 1.037, $\S 9^{\circ}$ a 13 do CPC) é aplicável também ao incidente de resolução de demandas repetitivas.

O objeto do recurso era definir se a decisão que suspende o processo em $1^{\circ}$ grau em virtude da instauração de incidente de resolução de demandas repetitivas no Tribunal é imediatamente recorrível por agravo de instrumento ao fundamento de distinção ou se, a exemplo do procedimento instituído para a hipótese de recursos especial e extraordinário repetitivos, é preciso provocar previamente o contraditório em $1^{\circ}$ grau e pronunciamento judicial específico acerca da distinção antes da interposição do respectivo recurso.

Colhe-se do voto da Relatora, Ministra Nancy Andrighi:

A despeito de incluídos em espaços topologicamente distintos e de ter havido previsão específica do procedimento de distinção em IRDR no PLC 8.046/2010 e que foi posteriormente retirada no Senado Federal, fato é que os recursos especiais e extraordinários repetitivos e o incidente de resolução de demandas repetitivas - IRDR - compõem um microssistema de julgamento de questões repetitivas, conforme se depreende do art. 928, I e II, do novo CPC [...].

Os vetores interpretativos que permitirão colmatar as lacunas eventualmente existentes em cada um desses mecanismos, de modo a integrá-los em um verdadeiro microssistema de julgamento de questões repetitivas, deverão ser, a meu juízo, a inexistência de vedação expressa no texto do novo CPC que inviabilize a integração entre os instrumentos e, ainda, a inexistência de ofensa a um elemento essencial do respectivo instituto, o que equivaleria a desnaturá-lo. $\mathrm{Na}$ hipótese em exame, não existe diferença ontológica e nem tampouco justificativa teórica para a assimetria entre a alegação de distinção formulada em virtude de afetação para julgamento sob o rito dos recursos repetitivos e em razão de instauração do incidente de resolução de demandas repetitivas.

Com efeito, ambos os requerimentos deverão ser formulados após a ordem de suspensão emanada pelo Tribunal e terão por finalidade a retirada da ordem de suspensão de processo que verse sobre questão distinta daquela submetida ao julgamento padronizado.

Em ambas as hipóteses, pois, pretende-se equalizar, de um lado, os princípios da isonomia e da segurança jurídica que decorrem do julgamento uniforme da questão repetitiva e, de outro lado, os princípios da celeridade, economia processual e razoável duração do processo que serão preservados quando se excluir da suspensão um processo que versa sobre matéria distinta da afetada.

O reconhecimento do microssistema de julgamento de questões repetitivas pela Corte Superior tem um alcance significativo no ordenamento jurídico brasileiro, na medida em que o STJ detém a função de uniformização da interpretação da lei federal. Contudo, é de se notar que a doutrina ${ }^{9}$ já havia sinalizado para o reconhecimento desse microssistema, do qual o IRDR faz

\footnotetext{
${ }^{9}$ Anote-se ainda a lição de Sofia Temer, quando discorre sobre a suspensão das demandas repetitivas e possibilidade de distinção e prosseguimento: “Ainda que suspensão decorra automaticamente da admissão do incidente, entendemos que não se dispensa a prolação de decisão nos processos pendentes, ainda que 'em bloco', com a respectiva intimação das partes acerca do sobrestamento. Entendemos aplicável, no silencio das disposições relativas ao IRDR, o art. 1.037 do CPC/2015, parágrafo $8^{\circ}$, relativo ao processamento dos recursos repetitivos. A intimação tem duas importantes funções: a) possibilita a atuação da parte para comprovar a distinção de seu caso; b) dá efetivo conhecimento à parte acerca da discussão do IRDR e faculta a sua participação no âmbito do incidente.”. (TEMER, Sofia. Incidente de
} 
parte, ao lado dos recursos especiais e extraordinários repetitivos, como se denota da lição de Mendes e Temer (2015, p. 283-331):

[...] caso os tribunais superiores já tenham afetado para julgamento em recurso especial ou extraordinário a mesma matéria do potencial incidente, não será admissível a sua instauração (art. 976, $\S 44^{\circ}$, do CPC/2015). A norma visa evitar a instauração desnecessária do incidente e decorre tanto da superioridade hierárquica das decisões dos tribunais de uniformização, como do reconhecimento de que o incidente faz parte de um microssistema processual de resolução de causas repetitivas (art. 928 do CPC/2015 e Enunciado 345 do $\mathrm{FPPC}^{10}$ ), devendo ser mantida a coerência desse sistema, primando-se também pela economia processual.

Para Azevedo (2018, p. 187-205) os recursos repetitivos e o IRDR "são elementos interdependentes, de modo a formarem um todo organizado, que é o microssistema brasileiro de gestão e julgamento de casos repetitivos", e complementa o autor, aduzindo pela possibilidade do distinguishing, nos termos da decisão do STJ alhures transcrita:

Dessa forma, o microssistema de julgamento de casos repetitivos serve a dois propósitos precípuos, o primeiro, da lacuna legislativa, ocorre quando um dos institutos necessitar de um dispositivo não previsto em seu regramento, nesse caso, poderá, em decorrência do microssistema, socorrer-se de dispositivos específicos de outros institutos também inseridos no microssistema. É o caso, por exemplo, do instituto da distinção (distinguish), em que não há previsão expressa nos artigos do $\mathrm{CPC} / 2015$, que tratam do IRDR, no entanto, devido ao microssistema de gestão e julgamento de casos repetitivos, esse instituto pode ser utilizado quando da instauração doIRDR, pois este poderáse socorrer da previsão expressa no $\S 9^{\circ}$ do art. 1.037 do CPC/2015, que trata do instituto da distinção para o recurso repetitivo, em decorrência do primeiro propósito da formação do microssistema.

Assim, no intuito de "gerir as causas repetitivas e viabilizar uma resposta uniforme a todos os processos que versem sobre a mesma questão de direito", o incidente de resolução e os recursos excepcionais repetitivos integram o microssistema de "tratamento coletivizado dos processos individuais que veiculam causa repetitivas" (MONNERAT, 2019, p. 163). ${ }^{11}$

Outro debate de suma importância na seara doutrinária, e mesmo em sede jurisprudencial, diz respeito sobre a constitucionalidade de aplicação do IRDR aos juizados especiais, seja pela vinculação a precedente já firmado, seja pela legitimação na instauração do incidente por órgãos integrantes do microssistema dos juizados especiais, ainda que a disposição legal do artigo 985, inciso I, do CPC, seja clara em declarar que a tese jurídica firmada no incidente será aplicada a todos os processos individuais ou coletivos que versem sobre idêntica questão direito e que

resolução de demandas repetitivas. 2. ed., rev., ampl. e atual. Salvador: Ed. JusPodivm, 2017. p. 128129).

${ }^{10}$ FPPC, Enunciado 345. O incidente de resolução de demandas repetitivas e o julgamento dos recursos extraordinários e especiais repetitivos formam um microssistema de solução de casos repetitivos, cujas normas de regência se complementam reciprocamente e devem ser interpretadas conjuntamente.

${ }^{11} \mathrm{O}$ autor assevera, ainda, que "As três técnicas referidas no at. 928 do CPC, possuem muito mais pontos em comum do que distinções, vez que são voltadas a cumprir os mesmos objetivos, quais sejam: gerir os processos repetitivos e proporcionar de maneira racional, eficiente e isonômica a mesma resposta a todos os jurisdicionados que se encontram na mesma situação no plano do direito material. Elas se diferenciam apenas pelo órgão competente para processar e julgar a causa e, por via de consequência, pelo alcance da autoridade (vinculante) do precedente nela formado.". 


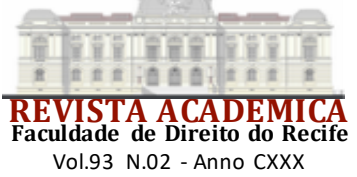

Não se pode perder de vista que os tribunais têm o dever de uniformizar sua jurisprudência e mantê-la estável, íntegra e coerente (art. 926 do CPC), assim, ainda que os juizados especiais possuam órgão recursal próprio, suas decisões devem estar em prefeita harmonia e coerência com a ordem jurídica, que é una, e somente dessa forma a jurisprudência se manterá integra, fortalecendo os microssistemas de julgamento de demandas repetitivas e o microssistema de precedentes obrigatórios.

Por fim, e não menos importante, uma questão de grande relevo nos bastidores doutrinários e jurisprudenciais atine à necessidade ou não de causa em trâmite no $2^{\circ}$ grau para a instauração do incidente de resolução de demandas repetitivas. Já na tramitação do anteprojeto do novo CPC houve uma controvérsia quanto ao texto aprovado no Senado Federal e na Câmara dos Deputados que envolvia a abrangência do juiz como legitimado e se haveria necessidade de se instaurar o IRDR a partir de processos que pudessem estar tramitando na $1^{\mathrm{a}}$ instância ou se apenas quando estivessem no tribunal, em razão de competência recursal ou originária.

No texto final aprovado foram excluídos todos os dispositivos que exigiam a presença prévia de processo em tramitação perante o tribunal - o que concerne ao tema de "pressupostos do IRDR", até mesmo porque a outra opção iria contra ao próprio objetivo do incidente, que é a uniformização da jurisprudência e gerar economia processual e segurança jurídica.

Para parte da doutrina, é dispensável a existência de causa pendente no tribunal para a instauração do IRDR, uma vez que o tribunal decide apenas questão jurídica, fixando tese vinculativa, e os casos concretos devem ser analisados pelo juiz natural, a exemplo de Temer (2017, p. 106-110) e Mendes (2017, p. 123-124). Outra parte defende essa necessidade, em suma, sob o argumento de que o parágrafo único do artigo 978 do CPC assenta que $\mathrm{O}$ órgão colegiado incumbido de julgar o incidente e de fixar a tese jurídica julgará igualmente o recurso, a remessa necessária ou o processo de competência originária de onde se originou o incidente, como se vê da lição de Didier Jr. e Cunha (2016, p. 639-640) e Cavalcanti (2016, p. 226-227).

Por sua vez, Ministros da Terceira Turma do Superior Tribunal de Justiça, por maioria, exararam entendimento nos autos do Recurso Especial no 1.631.846/DF, no sentido de não ser pressuposto de admissibilidade do IRDR a preexistência de recurso sobre a matéria pendente de julgamento no tribunal, bem como definiram não ser cabível recurso especial em face do acórdão que inadmite a instauração do IRDR por falta de interesse recursal do requerente, pois, apontada a ausência de determinado pressuposto, será possível a instauração de um novo IRDR após o preenchimento do requisito inicialmente faltante, sem que tenha ocorrido preclusão.

Em seu voto-vista, a Ministra Nancy Andrighi, relatora para acórdão, asseverou que o IRDR é um procedimento-modelo, no qual há fixação de teses jurídicas, e não julgamento de causas, de modo que os requisitos para sua instauração estão no art. 976, I e II, do CPC/2015. Portanto, não há exigência de pendente no Tribunal, e o art. 978 do CPC/2015 é apenas uma regra de prevenção.

Destaca-se trecho do voto do Ministro Marco Aurélio Bellizze, para quem causa pendente no tribunal não é requisito legal para a instauração do IRDR:

São muitas as discussões acerca da efetividade e da capacidade do IRDR para promover maior celeridade e uniformidade nas decisões, o que representa debate interessante e enriquecedor sobre esse instituto. Sob tal enfoque, ele resulta de uma aposta da Comissão de Juristas, em certa medida modificada pelos atores do Poder Legislativo.

Nesta ocasião, a Terceira Turma se depara com a necessidade de interpretar as regras sobre o IRDR e refletir sobre os requisitos para sua instauração.

Trata-se, portanto, de inegável oportunidade de se buscar a coerência e a concretude para esse novo instituto, no exercício de uma função de caráter tipicamente jurisdicional [...]

Todas essas razões permitem, então, considerar o IRDR um procedimento- 


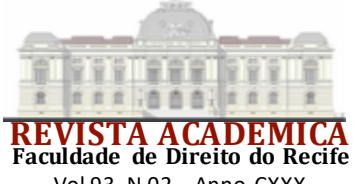

Vol.93 N.02 - Anno CXXX

O IRDR surgiu sob inspiração do modelo alemão Musterverfahren, e sua natureza jurídica é de um procedimento-modelo, quando após a escolha do processo líder, o incidente é instaurado para fins de fixação de tese jurídica em abstrato, que será aplicada aos casos presentes e futuros pelos juízes naturais dos processos por ele afetados, dentro da jurisdição do tribunal onde se processou o incidente de resolução. Este, por sua vez, somente pode ser instaurad o se preenchidos os requisitos de i) efetiva repetição de processos que contenham controvérsia sobre a mesma questão de direito e o (ii) risco de ofensa à isonomia e à segurança jurídica.

Certo é que o IRDR tem causado impacto na comunidade jurídica, gerando dúvidas e controvérsias sobre alguns pontos, e alguns deles já foram apreciados pelo Superior Tribunal de Justiça, órgão destinado à uniformização da interpretação da lei federal. Neste sentido, é importante registrar a decisão do STJ, acompanhando a sinalização da doutrina mais balizada, acerca do reconhecimento de um microssistema de julgamento de questões repetitivas, no qual o IRDR está incluso como mais uma opção de técnica processual com o fim de uniformização da jurisprudência, sobretudo nas lides coletivizadas, podendo se se socorrer da previsão expressa no $\S 9^{\circ}$ do art. $1.037 \mathrm{do}$ CPC/2015, no caso de necessidade de distinguishing.

Outra decisão digna de realce diz respeito sobre a constitucionalidade de aplicação do IRDR aos juizados especiais, e neste sentid o o CPC/2015 é enfático ao dispor que a tese fixada no IRDR se aplica aos juizados especiais, o que não gera maiores debates, todavia, o ponto de maior controvérsia se instala na possibilidade de o processo pendente de julgamento no juizado especial ser escolhido como o líder para a instauração do IRDR. Nesse jaez, o STJ firmou tese repetitiva a partir da afetação de recurso especial contra acórdão do TRF da $4^{\mathrm{a}}$ Região, exarado em sede de incidente de resolução de demand as repetitivas.

De igual forma, o STJ também proferiu decisão de grande ressonância atinente à necessidade ou não de causa em trâmite no $2^{\circ}$ grau para a instauração do incidente de resolução de demand as repetitivas. A terceira turma decidiu, por maioria, ser pressuposto de admissibilidade do IRDR a preexistência de recurso sobre a matéria pendente de julgamento no tribunal, sobretudo por considerarem o IRDR um procedimento-modelo, que se vale da técnica de cisão cognitiva, característica de tal parad igma. Assim, concluiu o STJ que os requisitos para instauração do IRDR nos tribunais são, apenas, aqueles previstos no art. 976 do CPC/2015.

\section{REFERÊNCIAS}

ABBOUD, Georges; CAVALCANTI, Marcos de Araújo. Inconstitucionalidades no incidente de resolução de demandas repetitivas (IRDR) e os riscos do sistema decisório. Revista de Processo, São Paulo, n. 240, fev. 2015.

ANDRADE, Ana Karenina Silva Ramalho. O IRDR e o juizado especial: são conciliáveis? In: WAMBIER, Luiz Rodrigues et al. (coord.). Código de processo civil no STF e no STJ: estudos sobre os impactos e interpretações. Salvador: Juspodvim, 2018. p. 45-70.

ARAÚJO, José Henrique Mouta. O incidente de resolução de causas repetitivas no novo CPC e o devido processo legal. In: MACEDO, Lucas Buril et al. (org.). Processos nos tribunais e meios de impugnação às decisões judiciais. Salvador: JusPodivm, 2015. Coleção Novo CPC, Doutrina Selecionada, v. 6.

ARENHART, Sérgio Cruz. A tutela coletiva de interesses individuais: para além da proteção dos interesses individuais homogêneos. 2. ed. rev. atual. e ampl. São Paulo: Revista dos

Tribunais, 2014.

AZEVEDO, Marcelo Tadeu Freitas de. A natureza jurídica do incidente de resolução de 
demand as repetitivas. Revista eletrônica [do] Tribunal Regional do Trabalho da $9^{a}$ Região, Curitiba, v. 7, n. 70, p. 187-205, jul. 2018.

CABRAL, Antonio do Passo. O novo procedimento-modelo (Musterverfahren) alemão: uma alternativa às ações coletivas. Revista de Processo, São Paulo, v. 147, p. 123-146, 2007.

CABRAL, Antonio do Passo. A escolha da causa-piloto nos incidentes de resolução de processos repetitivos. Revista de Processo, São Paulo, v. 231, p. 201-224, maio 2014.

CAMBI, Eduardo; FOGAÇA, Mateus Vargas. Incidente de Resolução de Demand as Repetitivas no novo Código de Processo Civil. Revista de Processo, São Paulo, v. 243, p. 333-362, maio 2015 .

CAVALCANTI, Marcos de Araújo. Incidente de resolução de demandas repetitivas (IRDR). São Paulo: Revista dos Tribunais, 2016. Coleção Leibman.

CUNHA, Leonardo José Carneiro da. Anotações sobre o incidente de resolução de demandas repetitivas previsto no Projeto do novo Código de Processo Civil. Revista de Processo, São Paulo, v. 193, p. 255-280, mar. 2011.

DIDIER JR., Fredie; CUNHA, Leonardo Carneiro da. Curso de direito processual civil. Salvador: Juspodivm, 2016. v. 3.

KOEHLER, Frederico. O incidente de resolução de demandas repetitivas e os juizados especiais. Revista de Processo, São Paulo, v. 237/497, nov. 2014.

LEMOS, Vinicius Silva. Incidente de resolução de demandas repetitivas. Londrina: Thoth, 2019.

MARINONI, Luiz Guilherme. Precedentes obrigatórios. 2. ed. São Paulo: Ed. RT, 2011.

MARINONI, Luiz Guilherme. Incidente de resolução de demandas repetitivas: decisão de questão idêntica x precedente. São Paulo: Editora Revista dos Tribunais, 2016.

MARINONI, Luiz Guilherme. Incidente de resolução e incidente de assunção de competência. Revista eletrônica [do] Tribunal Regional do Trabalho da 9a Região, Curitiba, v. 8, n. 79, p. 97-116, jun. 2019.

MARINONI, Luiz Guilherme. O "problema” do incidente de resolução de demandas repetitivas e dos recursos extraordinário e especial repetitivos. Revista de Processo, São Paulo, v. 249, ano 40, p. 399-419, nov. 2015.

MEDINA, José Miguel Garcia. Curso de direito processual civil moderno. 3. ed. rev. atual. e ampl. São Paulo: Editora Revista dos Tribunais, 2017.

MENDES, Aluisio Gonçalves de Castro. Ações coletivas e meios de resolução coletiva de conflitos no direito comparado e nacional. 4. ed. São Paulo: Ed. RT, 2014.

MENDES, Aluisio Gonçalves de Castro. Incidente de resolução de demandas repetitivas: sistematização, análise e interpretação do novo instituto processual. Rio de Janeiro: Forense, 2017. 


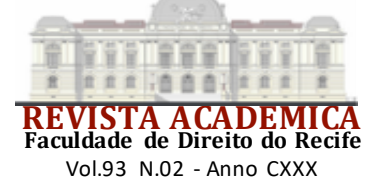

TRIGUEIRO, Victor Guedes (org.). Código de processo civil no STF e no STJ: estudos sobre os impactos e interpretações. Salvador: Juspodivm, 2018.

WAMBIER, Teresa Arruda Alvim. Distinção entre questão de fato e questão de direito para fins de cabimento de recurso especial. Revista de Processo, São Paulo, v. 92, p. 52-70, out./dez. 1998.

ZANETI JR., Hermes. Comentários aos arts. 926 a 928. In: CABRAL, Antonio do Passo; CRAMER, Ronaldo. Comentários ao novo Código de Processo Civil. Rio de Janeiro: Forense, 2015. p. 1336-1338. 